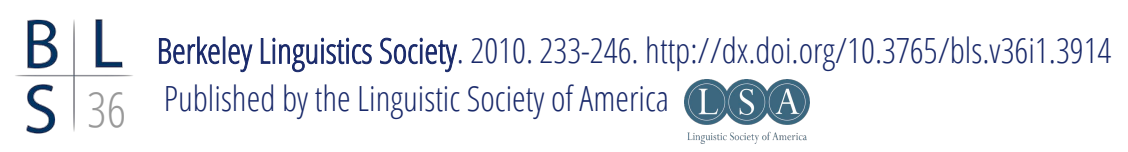

\title{
The Source-Goal Asymmetry in SLA
}

\author{
WOJCIECH LEWANDOWSKI \\ University of Copenhagen
}

\section{Introduction}

It has been shown in the literature on motion events that there is a strong tendency for speakers of different languages to express goals in preference to sources (e.g. Regier 1997, Ihara \& Fujita 2000) and that this linguistic asymmetry could have its origins in non-linguistic event representations (cf. Lakusta \& Landau 2005, Lakusta et al. 2007).

In this paper, it will be shown that the goal bias in language and cognition has important implications for SLA. In particular, the acquisition of the verbs come and go (henceforth, C\&G) by Polish speakers of Spanish L2 will be addressed.

As first shown by Fillmore (1971), C is a goal-oriented, while $\mathrm{G}$ is a sourceoriented verb, i.e., in a sentence like (1), the expression at 5 refers to the arrival time; in contrast in (2) it specifies the departure time.

\section{(1) a. John came home at 5. \\ b. John went home at 5 .}

On the other hand, it has been argued that $C \& G$ display a universal deictic contrast defined as motion toward the speaker vs. motion away from the speaker (cf. Talmy 2000). However, Lewandowski (2014) shows, against this hypothesis, that whereas such an analysis appropriately characterizes the lexical semantics of C\&G in Spanish, in Polish the use of C\&G relies on non-deictic factors: overall, $\mathrm{C}$ is preferred when the speaker adopts an arrival-oriented perspective, and $\mathrm{G}$ if the motion event is conceptualized from a source-oriented perspective, regardless of whether the goal of movement is constituted by the speaker or any other entity involved in the communication act. As a consequence, the author concludes that Polish speakers can choose to think about the same motion event from two different perspectives (that of arrival or that of departure), while no such possibility is available in Spanish, where motion toward the speaker needs to be described as goal-oriented and motion toward any other goal as source-oriented. A special case 


\section{Wojciech Lewandowski}

of use of $C \& G$ are the comitative contexts, i.e. situations in which the speaker asks the addressee to accompany him/her to a place: in Spanish such situations are conceptualized as motion toward the speaker and, consistently, the use of C is obligatory; in contrast, in Polish the source-oriented perspective is adopted and the use of $\mathrm{G}$ is required (cf. Lewandowski 2010).
a. ¿Te vienes conmigo al cine?
you come with me to the cinema
'Would you like to come to the cinema with me?'
b. Pójdziesz ze mną do kina?
you go with me to cinema
'Would you like to come to the cinema with me?'
(Spanish)
(Polish)

As noted by Lewandowski (2014), these linguistic facts reflect Slobin's (1996) "thinking for speaking" hypothesis, according to which different language patterns yield different patterns of thought in the process of producing and interpreting verbal expressions. As for C\&G in Polish and Spanish, the following conditions of use involving different "thinking for speaking" patterns can be distinguished: (i) motion toward the speaker in a source-oriented context (Polish $=\mathrm{G}$, Spanish $=\mathrm{C}$ ), (ii) motion toward any other goal in a goal-oriented context (Polish $=\mathrm{C}$, Spanish $=\mathrm{G}$ ) and (iii) comitative contexts (Polish $=\mathrm{G}$, Spanish $=\mathrm{C})$. The acquisition of $C \& G$ by Polish learners of Spanish thus implies restructuring these particular conditions of use.

The main hypothesis is that, if Lakusta \& Landau (2005) and Lakusta et al. (2007) are on the right track, then this process is constrained by the Goal-bias in spatial cognition, i.e. the shift from a source-oriented perspective to a goaloriented perspective should be easier than the other way around. In order to test it, an acceptability judgment task with 30 Polish learners of Spanish L2 of three different proficiency levels (low intermediate, high intermediate and advanced) and a control group of 10 Spanish native speakers was performed. It consisted of 6 grammatical sentences, 6 ungrammatical ones, representing the three conditions of use listed above, and 12 distractors. The task consisted in judging the acceptability of each sentence according to a Likert scale containing the values from -2 to +2 . The repeated measures ANOVA confirmed our hypothesis: no matter how advanced the level of Spanish L2 speakers was, they tended to judge incorrectly the sentences corresponding to the second condition; in contrast, the correct responses concerning the first and the third conditions increased significantly with the proficiency level.

This article is organized as follows. Section 1 gives an overview of the theoretical background of our study. In Section 2 we present the empirical base of our research, i.e., the behavior of C\&G in Polish and Spanish, and we formulate the 


\section{The Source-Goal Asymmetry in SLA}

hypothesis for our experiment, which is described in Section 3. Conclusions are drawn in Section 4.

\section{Theoretical Background}

The main argument that we would like to put forward in this paper relies on two hypotheses which were independently developed in psycholinguistic research on motion events, namely the non-linguistic goal path bias hypothesis and Slobin's (1996) "Thinking for speaking" hypothesis.

\subsection{Non-Linguistic Goal Path Bias}

Experimental data by Lakusta \& Landau's (2005) provide evidence that - in language - there is an asymmetric relationship between sources and goals in motion events. In particular, when children and adults describe motion events, they tend to encode goal paths (i.e., into $X$ ) in preference to source paths (i.e., from $X$ ). For example, manner of motion verbs appear more often with goal PPs than with source PPs, although both types of PP are optional.

This pattern holds not only for motion events, but also for change of possession events, change of state events and attachment and detachment events (in the sense of Levin 1993). For example, change of possession events are much more frequently described from a goal-perspective (e.g. buy) than from a sourceperspective (e.g. sell).

Additional evidence for this source-goal asymmetry comes from studies of brain-damaged children and adults. For example, Ihara \& Fujita (2000) reported that Japanese agrammatical speakers tend to drop source but not goal case markers, sometimes substituting the latter for the former. The bias to omit sources also extends to children with Williams syndrome (Landau \& Zukowski 2003) and children who are congenitally deaf and have received no exposure to a conventional language model (Zheng \& Goldin-Meadow 2002).

Finally, there are also cases where this bias influences grammar. For example, the semantics of a change of state verb specifies both source and goal, but the syntax "tends to render the source path optional" (Lakusta \& Landau 2005:28), while the omission of the goal leads to ungrammaticality (cf. also Nam 2004).

(3) a. The frog turned from green to blue.

b. The frog turned to blue.

c. *The frog turned from green.

Lakusta \& Landau (2005) conclude that the robustness of a goal bias in language raises the possibility that it might be an innate characteristic of our cognitive system. Indeed, Lakusta et al. (2007) found that 12-month-old children preferentially 


\section{Wojciech Lewandowski}

attended to the goals rather than to the sources, when watching motion events (they looked longer at motion scenes involving a change in the goal object), thus suggesting that the preference for goals rather than sources exists prelinguistically, i.e., before infants produce full linguistic structures for expressing motion events.

We suggest that, if the claim that goals are higher ranked than sources in human cognition is correct, then this asymmetry should have important implications for SLA. In particular, path-oriented linguistic structures should be acquired easier than source-oriented linguistic structures. Before going to the details of the present study, however, another piece of its theoretical background - Slobin's (1996) "Thinking for speaking" hypothesis - needs to be introduced.

\subsection{The "Thinking for Speaking" Hypothesis}

For the last decades research on first language acquisition has shown that children learning typologically different languages provide different amounts and different kinds of information when describing motion events. For instance, Slobin (1996) reported that English-speaking children use twice as many manner verbs as Spanish-speaking children, when talking about motion. This has been attributed to the fact that speakers of satellite-framed languages (such as English) pay more attention to the conflation of Motion and Manner than speakers of verb-framed languages (such as Spanish), in which Motion is usually conflated with the Path component in the verb root (cf. Talmy 1975, 1985, 2000).

(4) a. The bottle floated into the cave.

(English)

b. La botella entró en la cueva flotando.

(Spanish) the bottle entered in the cave floating

In order to account for this finding, Slobin (1996) has coined the term "thinking for speaking", which is defined as «a special form of thought that is mobilized for communication» (Slobin 1996:76) and, thus, refers to the role of the language in the process of expressing and interpreting verbal expressions. As rightly observed by Stam (1998), if it is true that linguistic categories play an important role in the shaping of concepts children are going to use in speaking, this would mean that learning a typologically different L2 involves learning another pattern of "thinking for speaking".

Providing evidence from the acquisition of $C \& G$ we will show that one important factor constraining the restructuration of the L1 thinking for speaking patterns is the non-linguistic goal path bias. A description of the empirical basis of our study follows in the next section. 


\section{COME and GO in Polish and Spanish}

It has been widely assumed that all languages have a class of motion verbs corresponding to English come and go and that these verbs lexicalize a universal deictic contrast (cf. Miller \& Johnson-Laird 1976, Talmy 2000, among many others).

For instance, in Talmy's (2000) framework C\&G are analyzed as a special type of Path-conflating verbs, in which the Path consists of the speaker as a Ground and a deictic vector. As Talmy (2000:56) claims, the deictic vector "typically has only the two member notions, 'toward the speaker' and 'in a direction other than toward the speaker"'. Hence C is assumed to denote inherently 'MOTION TOWARD THE SPEAKER' and G 'MOTION AWAY FROM THE SPEAKER'. These definitions imply, on the other hand, that both verbs are in complementary distribution.

However, as it has been argued by Lewandowski (2010), Talmy's claim is too simplifying, since there is cross-linguistic variation concerning the type of Ground encoded in C\&G: whereas in some languages it is constituted crucially by the speaker, in others the Ground may extend to other goals of movement. As a general rule, if such an extension of the deictic centre takes place, C\&G tend to alternate. Moreover, the author observes that Polish and Spanish are situated at two extremes of this "deicticity and complementarity scale" (cf. also Ricca 1993): whereas in the latter these verbs express the deictic opposition "motion towards the speaker" vs. "motion away from the speaker", in the former the use of one or the other verb relies on pragmatic factors related to a particular kind of conceptualization of the motion event. In particular, it has been shown by Lewandowski (2014) that the use of $\mathrm{C}$ is preferred when the speaker wishes to adopt the perspective of arrival, while $\mathrm{G}$ is used when the event is conceptualized from the perspective of departure, which is due to the different temporal orientation of C\&G (cf. (1)).

\subsection{C\&G in Spanish}

The Spanish coming verb venir typically describes motion toward the speaker's location, whereas the going verb ir is used in contexts of movement toward any other goal (cf. (5)).

$$
\begin{aligned}
& \text { a. Ven/ *ve aquí a las cuatro. } \\
& \text { come.IMP go.IMP here at four } \\
& \text { 'Come/*go here at four.' }
\end{aligned}
$$




\section{Wojciech Lewandowski}

b. Quién vendrá a vernos a ese lugar tan lejano? who will come to see us to that place so far-off 'Who will visit us in that far-off place?'

c. Ella fue $/ *$ vino a verlos a aquel lugar. she went came to see them to that place 'She visited them in that place.'

The spatial adverb aqui ('here') in (5a) indicates that the speaker is located at the goal of movement at the time when the sentence is uttered ("coding time" in Fillmore's 1997 terms). However, as shown in (5b), venir can describe not only motion toward the speaker's location at the coding time, but also toward the speaker's location at the time of the displacement ("reference time" in Fillmore's 1997 terms), that is, toward a place where the speaker will be situated when the displacement takes place. As may be deduced from (5a) and (5c), the Spanish going verb $i r$ is in complementary distribution with the verb venir: it refers only to motion toward a goal distinct from the speaker. ${ }^{2}$

Finally, a special case of motion towards the speaker are the so-called comitative contexts, i.e., situations in which the speaker asks the addressee to accompany him/her to a place. In Spanish the use of $\mathrm{C}$ is obligatory in such speech acts (cf. (2a)), since they involve, first of all, the addressee's displacement toward the speaker, while the displacement of both the event participants to another goal of movement may be regarded as a less salient property of their illocutionary force (the term is used in the sense of Austin 1975 and Holdcroft 1978).

To sum up, it should be stressed that Talmy's prediction about the lexical semantics of C\&G is fully borne out by the Spanish data, since in this language the verb venir describes uniquely motion toward the speaker as the Ground (at either the coding or the reference time), whereas ir refers to motion in a direction different from the speaker.

\subsection{C\&G in Polish}

As may be appreciated in (6), in Polish both types of verbs can be used in contexts of motion towards any Ground, i.e., the speaker $(6 a, 6 b)$, the addressee (6c, $6 \mathrm{~d}$ ) or a goal beyond the speech act participants (6e).

$$
\begin{aligned}
& \text { a. Jan przyszedł wczoraj do mnie. } \\
& \text { John came yesterday to me } \\
& \text { 'John came to my place yesterday.' }
\end{aligned}
$$

\footnotetext{
2 Lewandowski (2010: 79-80) shows that the alternation between $\mathrm{C}$ and $\mathrm{G}$ is apparently allowed when movement toward the speaker's location at the reference time is described, as in (5b). However, he argues that G typically involves the speaker's absence at the goal of movement, whereas $\mathrm{C}$ is clearly preferred when the speaker's presence at the goal of movement is implied.
} 


\section{The Source-Goal Asymmetry in SLA}

b. Powiedział jej, że byłem chory i żeby do mnie poszła. he told her that I was ill and that to me went 'He told her that I was ill and asked her to come to my place.'

c. Mówiłeś, że jak ktoś do ciebie przychodzi, you said that when somebody to you comes robisz się nerwowy. you get nervous

'You said that every time somebody goes to your place, you get nervous'

d. Najpierw poszli do biura i stamtąd poszli first they went to office and from there they went do ciebie.

to you

First they went to the office and from there they went to your place'

e. Jak tam impreza u Jana? Przyszło dużo ludzi?

what about party at John's place came many people

'What about the party at John's place? Did many people go?'

As mentioned, $\mathrm{C}$ is preferred when the speaker strongly identifies with the goal of movement and $\mathrm{G}$ - when the speaker focuses on the departure point.

In (6a) we can observe that when motion towards the speaker in a neutral context is referred to, $\mathrm{C}$ is usually used: since the speaker constitutes the goal of motion, it is natural for him/her to adopt his/her own - arrival-oriented - perspective. However, the use of $\mathrm{G}$ is also possible, e.g., when the speaker wishes to convey that he or she identifies with the source-oriented perspective of the person whose words he/she reports, as in (6b). In (6c) and (6d) the Ground is constituted by the addressee. In (6c) the arrival-perspective is taken due to the fact that the speaker relates the event, as in (6b), from the viewpoint of the person whose message is reported. On the other hand, in (6d) the departure perspective is taken because the source-path expression "from there", introduced previously in the discourse, determines the spatial orientation of the utterance. Similarly, although in (6e) the speaker is talking about a party in a place he did not go to, he uses $\mathrm{C}$, because the goal of movement has previously been introduced in the discourse and so it serves as a focal Ground of the narration in the mind of the speaker.

Finally, let us recall that in contrast to Spanish, comitative contexts in Polish require the adoption of a departure perspective, since, as illustrated in (2b), in such speech acts the use of $\mathrm{G}$ is obligatory.

In sum, in Polish it is possible to adopt two different perspectives (or construals, in Langacker's 1987 terms) when referring to the same objective spatial situation: the perspective of departure or the perspective of arrival. No such possibility is available in the case of the Spanish C\&G, where motion towards the speaker 


\section{Wojciech Lewandowski}

can be depicted uniquely from the perspective of the arrival point ( $\mathrm{C}$ is obligatory), whereas motion towards any other goal must be described from the perspective of the departure point ( $\mathrm{G}$ is required).

This cross-linguistic difference involves 5 different conditions of use of C\&G: 2 in which the same verbs are used in both languages (Condition 1 and 4 in (7)) and 3 in which the use of a different verb is required (Conditions 2, 3 and 5).

$$
\text { Conditions of use of C\&G in Polish and Spanish }
$$

\begin{tabular}{|l|c|c|}
\hline Goal of motion & Polish & Spanish \\
\hline 1. Speaker, neutral context & C & C \\
\hline 2. Speaker, departure perspective & G & C \\
\hline 3. Speaker, comitative context & G & C \\
\hline 4. Non speaker, departure perspective & G & G \\
\hline 5. Non speaker, arrival perspective & C & G \\
\hline
\end{tabular}

As argued by Lewandowski (2014), this phenomenon clearly reflects Slobin's (1996) idea that the resources of a given language determine (to a certain extent) the way the speaker can choose to think about a particular event when speaking about it.

\section{The Present Study}

As follows, a more detailed description of the present study is provided.

\subsection{Hypothesis}

Taking into account that there is possibly a pre-linguistic goal path bias in human cognition, as Lakusta \& Landau (2005) and Lakusta et al. (2007) suggest, we hypothesized that it would be easier for Polish learners of Spanish L2 to acquire those patterns of use of $\mathrm{C} \& \mathrm{G}$ which involve the shift from a source-oriented perspective to the goal-oriented one (cf. Conditions 2 and 3 in (7)) than the other way around (Condition 5).

\subsection{Participants}

The experimental group consisted of 30 learners of Spanish at different Polish universities, both male and female. For a participant's data to be included in the analysis all of the following criteria had to be fulfilled: (a) their level of Spanish was not lower than "low intermediate" in order to ensure that they could under- 
stand the experimental items, (b) Polish was the participant's reported native language and (c) the participant had not stayed in a bilingual Spanish autonomous region for more than ten days. The last criterion was thought to prevent the possible inferences with other peninsular languages, such as e.g. Catalan, where $C \& G$ behave differently than in Spanish (cf. Lewandowski 2010). 10 native speakers of Spanish acted as a control group. Only Spanish was their reported native language and they had never lived in a bilingual Spanish autonomous region.

\subsection{Testing Instruments}

We verified our hypothesis using a packet that consisted of (i) a language experience questionnaire, (ii) a cloze test and (iii) an acceptability judgment task designed to test the hypothesis formulated in 3.1. The objective of the language questionnaire was to exclude from the experiment those participants which did not meet the criteria described in 3.2. On the other hand, the cloze test was used in order to measure the participants' proficiency level in Spanish. And finally, the main hypothesis was tested by means of an acceptability judgment task, consisting of 6 sentences and the same number of distractors. The experimental items clearly reflected Conditions 2,3 and 5 (cf. (7)). Two items per Condition, one grammatical and one ungrammatical, were included (cf. (8)).

(8) a. En la universidad. Carmen está hablando con Juani.

At the university. Carmen is talking to Juani.

Hola, Juani. ¿Cómo estás? ¿Qué tal la fiesta en casa

hello Juani how you are how the party at home

de Juan? ¿Fue mucha gente? Yo al final tuve que

John's went many people I in the end had to

quedarme en casa.

stay at home

'Hi, Juani! How are you? What about the party in John's place? Did

many people go? In the end I had to stay home.

(Condition 5, grammatical sentence)

b. Carmen y Juani hablan por teléfono. Carmen está en la universidad y Juani en casa.

Carmen and Juani are speaking on the phone. Carmen is at the university and Juani is at home.

Juani: Oye, Carmen, esta noche hago una fiesta en mi casa.

Juani hear Carmen this night I do a party in my home

¿Te quieres pasar?

you want come

'Juani: Listen, Carmen. I am organizing a party this night in my place.

Would you like to come?' 


\section{Wojciech Lewandowski}

Carmen: Claro que sí, pero vendré sobre las once.

Carmen clear that yes but I will come about eleven

'Carmen: Sure, but I will come about eleven.'

(Condition 5, ungrammatical sentence)

The order of the experimental items was counterbalanced across different participants. Below each sentence there was a Likert scale with values from -2 to +2 in order to judge a given item as "sounds awkward" for " -2 ", "sounds bad" for "-1", "I don't know" for " 0 ", "sounds okay" for " +1 " and "sounds perfect" for " +2 ".

\subsection{Procedure}

The data were collected between August and October 2009 via an on-line video conference. First, all the participants answered a language experience questionnaire and after that they took the cloze test. Next, they were presented with the acceptability judgment task and asked to judge the sentences on a Likert scale from -2 for completely unacceptable to +2 for perfectly acceptable, according to their first impression. Precise instructions with examples not related to the sentences at issue were provided in order to explain the reasons why a sentence should be considered acceptable or unacceptable. The participants took ca. 15 minutes to complete the acceptability judgment task and they were not allowed to go back and modify the responses.

\subsection{Results and Discussion}

The results of the experiment are graphically represented in (9). The vertical axis represents the percentage of errors, the horizontal axis the three conditions of use of C\&G taken into account in the experiment (cf. (7)), whereas the columns on the graph depict the proficiency levels: G1 stands for "low intermediate", G2 for "high intermediate", G3 for "advanced" and G4 for the control group.

(9) Results of the acceptability judgment task.

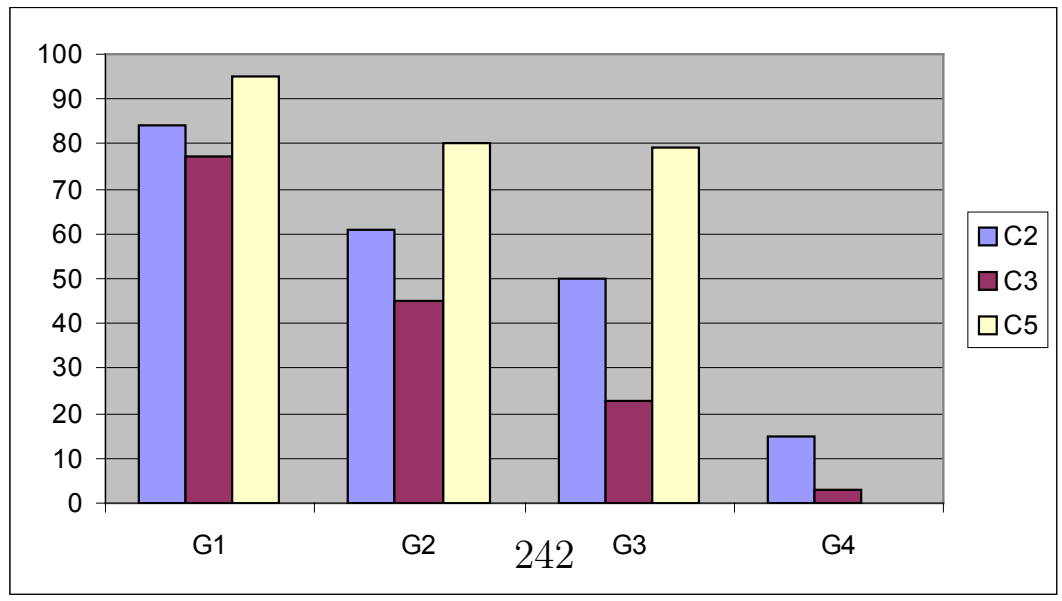


First of all, the Test of Between-Subject Effects reveals that there are significant differences between Conditions, Groups and there is also a significant interaction between Groups and Conditions ( $\mathrm{p}<0.05$ for all these cases), but no significant interaction between subjects within a given group was found $(\mathrm{p}=0.86)$.

As far as the interaction between Conditions and Groups is concerned (cf. (9)), it can be observed that Polish speakers of Spanish clearly follow the Polish patterns of use of $\mathrm{C} \& \mathrm{G}$ when motion toward a non-speaker from a goal-oriented viewpoint is described (Condition 5), independently of the level of proficiency. Polish requires the use of $C$ under this condition, whereas in Spanish G is obligatory. The results show that it is practically impossible for Polish native speakers to learn this condition of use, since even the advanced learners group make almost the same amount of errors as the low intermediate group $(95 \%$ vs. $79 \%$ of incorrect responses). The repeated measures ANOVA indicates that the difference between all the Polish learners groups and the Spanish control group is statistically significant ( $\mathrm{p}=0.000$ for all the proficiency levels).

The situation is quite different in the case of Condition 2. Although none of the proficiency groups acquired a native speaker-like command of this condition of use and there is a significant difference between the answers of the control group and all the proficiency levels ( $\mathrm{p}=0.000$ for all cases), a slight progression is observed, since the percentage of error decreases from about $84 \%$ to $50 \%$. Quite interestingly, also the Spanish control group gave incorrect responses in the 15\% of cases.

Analogously, a clear progression in the acquisition of Condition 3 is observed, since the percentage of errors decreases from $77 \%$ to $23 \%$. From the statistical viewpoint, there is a significant difference between the answers of the control group and the low intermediate and high intermediate proficiency levels $(p=0.000)$, but there is no significant difference between the answers of the control group and those of the advanced learners of Spanish ( $\mathrm{p}=0.07)$.

Thus our hypothesis is borne out. Undoubtedly, there is L1 thinking for speaking influence in the acquisition of all the conditions of use of C\&G by Polish speakers of Spanish L2 even at advanced stages. However, as expected, the L1 thinking for speaking patterns involving the shift from $\mathrm{G}$ to $\mathrm{C}$ (Conditions 2 and 3 ) are easier to be restructured than the thinking for speaking patterns involving the shift from $\mathrm{C}$ to $\mathrm{G}$ (Condition 5). In our view, this is due to the goal-bias in human cognition, since the use of $\mathrm{C}$ instead of $\mathrm{G}$ implies adopting a new thinking for speaking pattern focusing on the final point of movement, whereas the use of $\mathrm{G}$ instead of $\mathrm{C}$ involves adopting a new source- or departure-oriented perspective. 


\section{Wojciech Lewandowski}

\section{Concluding remarks}

In this paper we reported on the results of an experimental study dealing with the acquisition of C\&G by Polish speakers of Spanish as L2. We conducted an acceptability judgment task involving three conditions of use of these verbs (Conditions 2, 3 and 5, summarized in (7)) in order to verify the hypothesis of whether a source-goal asymmetry in human cognition is involved in SLA. The results of our experiment clearly support this hypothesis, since we observed a certain progression in the acquisition of the conditions entailing the shift from a source-oriented perspective $(\mathrm{G})$ to the goal-oriented perspective (C) as language proficiency increases (Condition 2 and Condition 3). In contrast, no progression in the acquisition of the condition involving the shift from the goal-oriented perspective to the source-oriented one (Condition 5) was found.

\section{References}

Austin, John. 1975. How to do things with words. Oxford: Oxford University Press.

Fillmore, Charles. 1971. Santa Cruz Lectures on Deixis. Bloomington: Indiana University.

Fillmore, Charles. 1997. Lectures on deixis. Stanford: CSLI.

Holdcroft, David. 1978. Words and Deeds. Problems in the Theory of Speech Acts. Oxford: Oxford University Press.

Ihara, Hiroko and Ikuyo Fujita. 2000. A cognitive approach to errors in case marking in Japanese agrammatism: The priority of the goal -ni over the source.

In A. Foolen and F. van der Leek, eds., Constructions in Cognitive Linguistics: Selected papers from the fifth international cognitive linguistics conference, 123-140, Amsterdam: John Benjamins.

Lakusta, Laura, and Barbara Landau. 2005. Starting at the end: The importance of goals in spatial language. Cognition 96:1-33.

Lakusta, Laura, Laura Wagner, Kirsten O'Hearn and Barbara Landau. 2007. Conceptual Foundations of Spatial Language: Evidence for a Goal Bias in Infants. Language learning and development 3(3):179-197.

Landau, Barbara and Andrea Zukowski. 2003. Objects, motions, and paths: Spatial language in children with Williams syndrome. Developmental Neuropsy- 
chology 23(1/2):107-139.

Langacker, Ronald. 1987. Foundations of Cognitive Grammar. Theoretical Prerequisites. Stanford: Stanford University Press.

Levin, Beth. 1993. English Verb Classes and Alternations. Chicago: University of Chicago Press

Lewandowski, Wojciech. 2010. Questioning the universality of deictic oppositions: come and go in Polish, Spanish and other languages. In I. Navarro and A. J. Silvestre, eds., Language systems and cognitive perspective, 75-92, Valencia: Tirant lo Blanch.

Lewandowski, Wojciech. 2014. Deictic verbs: typology, thinking for speaking and SLA. SKY Journal of Linguistics 27:43-65.

Miller, George and Philip Johnson-Laird. 1976. Language and perception. Cambridge: Cambridge University Press.

Nam, Seungho. 2004. Goal and source: asymmetry in their syntax and semantics. Paper presented at the Workshop on Event Structures in Linguistic Form and Interpretation, Leipzig, 18-3-2004.

Ricca, Davide. 1993. I verbi deittici di movimento in Europa: una ricerca interlinguistica. Firenze: La Nuova Italia Editrice.

Slobin, Dan. 1996. From 'thought and language' to 'Thinking for speaking'. In J. Gumperz and S. Levinson, eds., Rethinking Linguistic Relativity, 70-96, Cambridge: Cambridge University Press.

Stam, Gale. 1998. Changes in patterns of thinking about motion with L2 acquisition. In Serge Santi, et al., eds., Oralité et gestualité, 615-619. Paris: L'Harmattan.

Talmy, Leonard. 1975. Semantics and syntax of motion. In J. Kimball, ed., Syntax and semantics 4, 181-238. New York: Academic Press.

Talmy, Leonard. 1985. Lexicalization patterns: Semantic structure in lexical forms. In T. Shopen, ed., Language typology and lexical description 3, 36-149, Cambridge: Cambridge University Press.

Talmy, Leonard. 2000. Toward a cognitive semantics 2. Cambridge: MIT Press. 


\section{Wojciech Lewandowski}

Zheng, Mingyu and Susan Goldin-Meadow. 2002. Thought before language: How deaf and hearing children express motion events across cultures. Cognition 85(2):145-175.

University of Copenhagen

Department of English, Germanic and Romance Studies

Njalsgade 128

2300 Copenhagen $\mathrm{S}$

Denmark

woj.lewandowski@gmail.com 